\title{
Pengaruh Celebrity Endorser dan Iklan Instagram Terhadap Keputusan Pembelian Produk Wardah (Studi kasus pada Follower instagram Wardah Beauty)
}

\author{
Susi Susanti ${ }^{1}$, Sutama Wisnu Dyatmika ${ }^{2}$ \\ Universitas PGRI AdiBuana Surabaya ${ }^{1,2}$ \\ susisusand20@gmail.com
}

\begin{abstract}
ABSTRAK
Penelitian ini memiliki tujuan atas menganalisa pengaruh Celebrity Endorser dan Iklan Instagram kepada keputusan pembelian produk Wardah ( Studi kasus pada follower instagram Wardah Beauty). Penelitian kuantitatif adalah metode penelitian yang di pakai di penelitian ini. Sampel yang di gunakan sebanyak 110 responden. Di peroleh hasil penelitian data bahwasanya ke 3 Hipotesis memperlihatkan Hipotesis yang pertama yaitu Celebrity Endorser berpengaruh secara positif kepada keputusan pembelian produk Wardah dengan nilai signifikansi sebanyak 0,000, Hipotesis kedua yaitu iklan instagram mempunyai pengaruh kepada keputusan pembelian produk Wardah dengan nilai signifikansi sebesar 0,002, dan hipotesis ketiga Celebrity Endorser dan iklan instagram mempengaruhi positif secara simultan terhadap keputusan pembelian produk Wardah dengan nilai signifikansi sebebsar 0,000 dari hasil yang telah di lakukan pengujian memperlihatkan bahwa Celebrity Endorser dan iklan Instagram mempengaruhi signifikan dan positif secara simultan kepada keputusan pembelian produk Wardah (studi kasus pada follower instagram Wardah Beauty).
\end{abstract}

Kata kunci : Celebrity Endorser, Iklan Instagram, Keputusan Pembelian.

\begin{abstract}
This research aims to analyze the influence of Celebrity endorser and instagram Ads on Wardah product purchasing decisions (case study on Wardah Beauty Followers). Quatitative research a research method used in this study. The sample in this study used 110 respondents. The research results obtained that the $3^{\text {rd }}$ Hypotesis shows that the first Hypotesis is Celebrity Endorser which positively influences the purchase decision of Wardah products with a signifancace value of 0,000, the second Hypotesis is that instagram advertising has an influence on the purchasing decisions of Wardah products with a significance value of 0.002 , and the Hypotesis of third Celebrity endorser and instagram Ads simultaneously have positive influence on the purchase decision of Wardah products with a significance valuee of 0.000 from of the tests showed that Celebrity endorser and instgaram Ads have a positive and significant effect simultaneously purchase of Wardah products (case study on Followers) Wardah beauty instagram.
\end{abstract}

Keyword : Celebrity endorser, Instagram Ads, Purchasing decisions

\section{PENDAHULUAN}


Perkembangan dunia bisnis saat ini meningkat cukup pesat terutama industri kecantikan, di zaman yang serba modern sekarang ini wanita-wanita yang bekeinginan merawat wajahnya agar bisa tampil cantik dan menarik tidak jarang dari mereka yang menganggap tampilan cantik dan menarik bisa mendukung sikap percaya diri karena penampilan merupakan bebrapa hal yang berguna sebagai daya pikat tersendiri. Maka dari itu banyak perusahaan-perusahaan yang mengeluarkan berbagai produk kecantikan. Dengan adanya bermacam-macam bran yang melebar luas di dunia, pembeli menjadi sangatlah teliti untuk mencari produk kecantikan.

Produk yang di pakai konsumen pun yang menurut dirinya sempurna, bermacam merek produk kecantikan yang ada pada saat ini berkeinginan mempertahankan produknya untuk melampaui produk yang lain, melihat banyaknya produk yang melakukan pertarungan pasar yang semakin sengit untuk mendapatkan posisi yang paling unggul. Tidak heran jika pelaku bisnis saat ini melakukan promosi besar-besaran, termasuk Wardah yang Bertujuan untuk memenuhi kebutuhan masyarakat akan kosmetik berlebel halal.

Wardah mengandung tiga prinsip yaitu:

1. Bahan baku yang terdapat dalam kandungan produk wardah adalah terpercaya serta sudah ada kehalalannya., Di ciptakan sebagai kenyaman bagi penggunanya.

2. dalam berkembangnya Wardah yang berkreativitas memberikan jawaban semua harapan kosmetik perempuan yang tidak membuang kehalalannya dalam unsurnya.

3. kosmetik bukan hanya untuk kecantikan di luar saja akan tetapi juga kecantikan dalam jiwa. semua produk kecantikan Wardah telah memenuhi standard kesehatan dan aman digunakan.

Tiga prinsip Wardah tidak akan berjalan dengan lancar apabila tanpa bantuan Celebrity endorser.

Celebrity endorser sangat penting untuk menyampaikan pesan dalam konsep masa kini, sudah banyak perusahaan yang menggunakan Celebrity endorser untuk memperkenalkan produknya kepada konsumen agar dapat mencapai target penjualan. Beberapa cara yang dapat di laksanakan perusahaan ialah memakai Celebrity endorser dengan sesuai karakteristik produk sebagai bintang iklan produk tersebut. Selebriti sangat membantu dalam kelancaran pemasaran sebuah produk. Hal itu diperkuat dengan adanya fans atau sekolompok orang yang mengidolakan selebriti yang nantinya akan digunakan untuk memasarkan produk tersebut.

Selebriti pastinya akan membantu konsumen menjadi lebih dekat dengan produk. Seperti halnya Wardah menggunakan Celebrity endorser yang cantik dan anggun. Selebriti apabila memiliki mempunyai kredibilitas yang mendukung faktor yang ahli dapat di percaya dan di sukai maka akan sangat mempengaruhi, Dalam pesan yang yang akan di beritahukan, di harapkan nantinya sang selebriti dalam brand awareness dan brand recognition dapat mempunyai dampak, (Royan, 2004:8). Maka dari itu seorang yang memiliki bisnis atau seorang pemasar di harapkan lebih teliti dalam memilih seorang selebriti 
Salah satu channel yang di pakai untuk memasarkan sebuah produk yang terkenal adalah media sosial pemasaran. Produk yang menarik perhatian konsumen pasti mencari berbagai informasi lainnya, mereka akan mencari sebuah informasi yang berhubungan dengan produk yang dibutuhkan.

Ada bermacam - macam sosial media yang dapat tergunakan untuk menjadi alat untuk menjalankan bisnis yang cocok sebagai media untuk menginformasikan produknya dengan sempurrna, diantaranya adalah Instagram yang memang saat ini sedang banyak diminati. Menurut data.

Mastel dan APJII 2016, aplikasi sosial media terbanyak yang di gunakan, sebanyak 82 persen adalah aplikasi instagram sehingga facebook tertinggal. Dapat tersimpulkan bahwa sosial media dibutuhkan untuk berinteraksi bersama dengan orang lain, memakai bisnis online bisa melebarkan peluang pasar. Jadi dapat dikatakan bahwa pasar di sosial media khususnya Instagram juga bisa dipakai untuk memperoleh calon pembeli baru, hal itu dimanfaatkan oleh pelaku bisnis agar bisa memasarkan produk mereka melalui Instagram supaya konsumen dapat lebih terhubung dengan mereka., terlebih lagi instagram mempunyai filter video dan isntastory membuat pemasar dapat lebih memberiktahukan keunggulan produk mereka dibanding hanya dengan memakai foto. Meskipun durasi vidio pendek akan menjadi tantangan tersendiri bagi pemasar dalam menerapkan strategi untuk menginformasikan merknya hingga detail dan efektif agar konsumen tertarik serta membeli dan memperoleh dengan banyak follower, dan juga agar informasi yang akan tersampaikan lewat iklan di sosial media Instagram dengan baik dapat di terima oleh konsumen, semakin sempurna membuat konten dan bertambahnya jumlah pengikut /follower sebuah produk. Akan semakin gampang produk tersebut dalam memajukan strategi dan menciptakan konsep produk yang bagus di situs online. Banyaknya fitur yang ada di instagram sebagai periklanan yang sangat efesien untuk menginformasikan sebuah produk terhadap pembeli.

Pembeli mulai untuk melakukan proses pembelian pada saat mereka mulai mengenal sebuah masalah atau kebutuhan untuk dirinya. Maka dari itu pemasar berusaha menginformasikan produknya secara detail sehingga konsumen nantinya akan tertarik dan melakukan keputusan pembelian setelah mengetahui produk yang dia butuhkan, karena keputusan pembelian berawal dari ketertarikan seorang konsumen pada sebuah produk dan produk tersebut bisa memenuhi kebutuhannya

Permasalah yang terjadi yaitu karena pada saat sekarang ini banyak sekali pelaku bisnis yang melakukan promosi tak jarang mereka hingga membayar mahal untuk mempromosikan produknya lewat Celebrity endorser dan iklan instagram agar produk mereka dapat tersebar luas kepada masyarakat hal tersebut juga di lakukan Wardah Beauty karena dengan menggunakan media promosi seperti Instagram dan Celebrity endorser akan sangat mungkin bisa lebih membuat masyarakat mengenal produk Wardah. Terlandasan dengan latar belakang yang ada. Di tulislah oleh peneliti dengan judull: "Pengaruh Celebrity Endorser dan Iklan Instagram Terhadap Keputusan Pembelian Produk Wardah (studi kasus pada follower Wardah Beauty)".

penelitian yang di lakukan sebelumnya mempunyai hasil yang berjudul "pengaruh Celebrity endorser, brand image, brand trust terhadap keputusan pembelian clear shampoo di kota Denpasar. 
". Menunjukan bahwa Celebrity endorser positif memiliki pengaruh yang signifikan terhadap keputusan pembelian clear shampoo. Penelitian ini sudah terteliti oleh Wulandari and nurcahya (2015). sedangkan penelitian yang pernah di lakukan oleh Wiwik widiyanti (2017) Melakukan Penelitian yang bertema "Pengaruh kualitas produk, citra merek dan media iklan instagram terhadap keputusan pembelian produk ninebox (studi kasus pada follower Instagram @tempattasdotcom). "memperlihatkan iklan instagram positif memiliki pengaruh yang signifikan terhadap keputusan pembelian produk ninebox.

Rumusan masalah yang di ambil peneliti adalah sebagai berikut:

(1), Apakah Celebrity Endorser terpengaruhi terhadap keputusan pembelian produk Wardah? (2). Apakah Iklan Instagram terpengaruhi terhadap keputusan pembelian produk Wardah?. (3). Apakah Celebrity Endorser dan iklan instagram memiliki pengaruh yang bersamaan terhadap keputusan pembelian produk Wardah?.

rumusan masalah yang terdapat dalam penelitian ialah mempunyai tujuan: ingin melihat apakah (1), Celebrity Endorser terpengaruh terhadap keputusan pembelian produk Wardah. (2). Ingin melihat apakah keputusan produk Wardah pembelian terpengaruh dari iklan instagram. (3). Ingin melihat apakah Celebrity Endorser dan iklan instagram mempunyai pengaruh secara bersamaan terhadap keputusan pembelian produk Wardah

\section{TINJAUAN PUSTAKA DAN HIPOTESIS}

Menurut Shimp (2003:460) Celebrity endorser adalah menggunakan orang untuk di jadikan sebuah iklan atau tokoh terkenal (public figure) dalam suatu iklan yang di dukung.

simp (2014:192) menyatakan bahwa periklanan di definisikan sebagai berikut: periklanan adalah komonikasi berbayar dalam bentuk termediasi dari sumber yang di perpercaya yang sengaja dibuatkan untuk memberi pengaruh yang meerima atau target agar bisa melakukan apa yang menjadi keinginan pembuat iklan baik itu saat ini atau dimasa yang akan datang

Frommer, (2010) dalam Widiyanti (2017) menyatakan Instagram adalah sebuah aplikasi yang mempunya foto yang dapat di bagikan yang bisa membuat pengguna memperoleh foto, menerapkan bermacam-macam filter, dan membaginya kepada berbagai layanan media sosial, termasuk kepunyaan Instagram itu sendiri.

Menurut Kotller dan Amstrong (2008:181) keputusan pembelian (purchase decision) adalah membelikan merek yang sangat di sukai, dalam dua faktor yang dapat berada di antara niat pembelian dan keputusan pembelian.

berikut adalah kerangka konseptual di dalam penelitian ini yang telah di susun sebagai berikut:

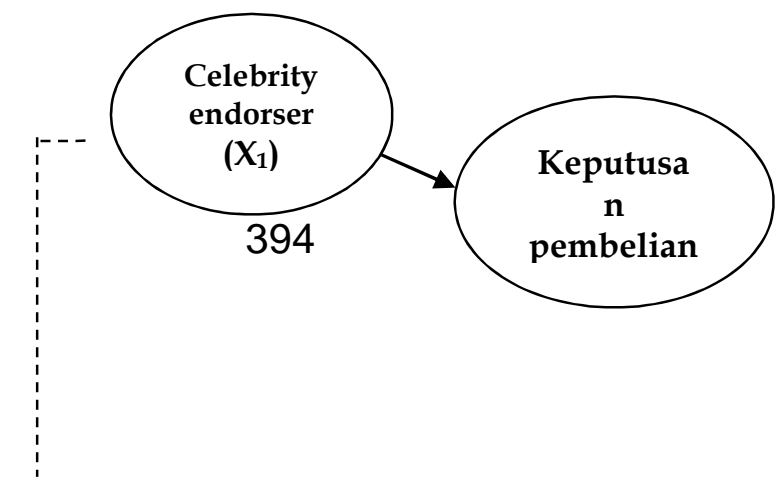




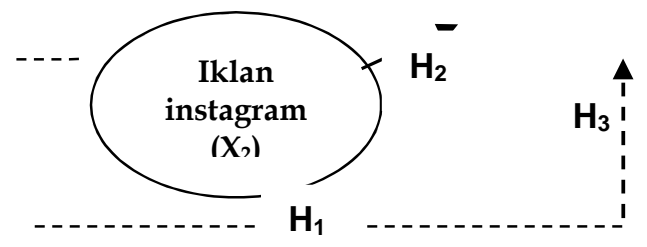

Gambar 1. Kerangka Konseptual

Di bawah ini adalah hipotesis yang gunakan dan pengambilannya dari rumusan masalah, adalah sebagai berikut:

$\mathrm{H}_{1}$ :Di duga keputusan pembelian produk Wardah terpengaruh dari Celebrity endorser.

$\mathrm{H}_{2}$ : Di duga iklan instagram memiliki pengaruh terhadap keputusan pembelian produk Wardah.

$\mathrm{H}_{3}$ : Di duga Celebrity Endorser dan iklan instagram terpengaruh secara simultan (bersama - sama) terhadap keputusan pembelian.

\section{METODE}

metode kuantitatif adalah metode yang di pakai. tiga variabele yang terdapat dalam penelitian yaitu Celebrity Endorser (X1) dan iklan instagram (X2) adalah variabel bebas dan keputusan pembelian (Y) adalah variabele terikat. Penelitian ini di lakukan pada instagram @WardahBeauty Populasi di dalam penelitian ini adalah Follower instagram WardahBeauty. Banyalnya sampel yang di pakai 110 responden yang memakai rumus Ferdinand yaitu indikator di kali 5 sampai 10 (Ferdinand, 2014:55). Peneliti menggunakan teknik Nonprobability sampling (Non random sampling) dan teknik purposive sampling. Pengambilan teknik yang di pakai dalam penelitian ini yaitu memakai penyebaran kuesioner yang berupa kuesioner online menggunakan google form. Jenis data yang di gunakan peneliti yaitu data primerlah dan data sekunder. Perolehan data primer oleh peneliti yaitu dengan cara menyebarkan kuesioner memkai skala likert. Data sekunder yang diperoleh penulis dalam penelitan ini yaitu dari sumber-sumber lain yang bisa mendukung penelitian ini. teknik analisis yang di gunakan peneliti yaitu berupa linier berganda regresi, oleh kerjasama SPSS softwer versi25

\section{HASIL}

Dengan berdasarkan hasil yang telah di teliti yang telah dilaksanakan kepada 110 responden pada follower instagram @Wardahbeauty dengan menyebarkan kuesioner online yaitu menggunakan google form, adapun Uji uji yang di pakai adalah sebagai berikut:

\section{Uji Validitas}

didalam penelitian yang di lakukan ini menguji validitas ialah untuk menguji apakah variabel dengan indikatornya adalah valid, berikut adalah uji validitas. 
Tabel 1

Uji Validitas Celebrity endorser (X1) dan iklan instagram (X2) keputusan pembelian (Y)

\begin{tabular}{|c|c|c|c|}
\hline Iteme & $\begin{array}{c}\text { Indi } \\
\text { kato } \\
r\end{array}$ & $\begin{array}{l}r- \\
\text { hitung }\end{array}$ & $\begin{array}{c}\mathrm{r}- \\
\text { tabel }\end{array}$ \\
\hline \multicolumn{4}{|c|}{ Celebrity endorser $\left(X_{1}\right)$} \\
\hline 01 & $\mathrm{XI}, 1$ & 0,805 & 0.2 \\
\hline 02 & $\mathrm{XI}, 2$ & 0,817 & 0,2 \\
\hline 03 & $\mathrm{XI}, 3$ & 0,822 & 0.2 \\
\hline 01 & $\mathrm{XI}, 1$ & 0,806 & 0.2 \\
\hline 02 & $\mathrm{XI}, 2$ & 0,838 & 0.2 \\
\hline 03 & $\mathrm{XI}, 3$ & 0,793 & 0.2 \\
\hline 01 & $\mathrm{XI}, 1$ & 0,797 & 0.2 \\
\hline 02 & $\mathrm{XI}, 2$ & 0,665 & 0.2 \\
\hline 03 & $\mathrm{XI}, 3$ & 0,862 & 0.2 \\
\hline 01 & $\mathrm{XI}, 1$ & 0,801 & 0.2 \\
\hline 02 & $\mathrm{XI}, 2$ & 0,798 & 0.2 \\
\hline 03 & $\mathrm{XI}, 3$ & 0,906 & 0,2 \\
\hline
\end{tabular}

\begin{tabular}{|c|c|c|c|}
\hline \multicolumn{4}{|c|}{ Iklan instagram $\left(\mathrm{X}_{2}\right)$} \\
\hline 01 & $\mathrm{XI}, 1$ & 0,907 & 0.2 \\
\hline 02 & $\mathrm{XI}, 2$ & 0,856 & 0.2 \\
\hline 03 & $\mathrm{XI}, 3$ & 0,669 & 0.2 \\
\hline 01 & $\mathrm{XI}, 1$ & 0,910 & 0.2 \\
\hline 02 & $\mathrm{XI}, 2$ & 0,911 & 0.2 \\
\hline 03 & $\mathrm{XI}, 3$ & 0,891 & 0.2 \\
\hline
\end{tabular}




\begin{tabular}{cccc}
\hline 01 & $\mathrm{XI}, 1$ & 0,891 & 0.2 \\
\hline 02 & $\mathrm{XI}, 2$ & 0,917 & 0.2 \\
\hline 03 & $\mathrm{XI}, 3$ & 0.905 & 0.2 \\
\hline \multicolumn{3}{l}{ Keputusan pembelian(Y) } \\
\hline 01 & $\mathrm{YI}, 1$ & & 0.2 \\
\hline 02 & $\mathrm{YI}, 2$ & 0,845 & 0.2 \\
\hline 03 & $\mathrm{YI}, 3$ & 0,812 & 0.2 \\
\hline 01 & $\mathrm{YI}, 1$ & 0,593 & 0.2 \\
\hline 02 & $\mathrm{YI}, 2$ & 0,817 & 0.2 \\
\hline 03 & $\mathrm{YI}, 3$ & 0,806 & 0.2 \\
\hline 01 & $\mathrm{YI}, 1$ & 0,872 & 0.2 \\
\hline 02 & $\mathrm{YI}, 2$ & 0,729 & 0.2 \\
\hline 03 & $\mathrm{YI}, 3$ & 0,845 & 0.2 \\
\hline 04 & $\mathrm{YI}, 1$ & 0,859 & 0.2 \\
\hline 05 & $\mathrm{YI}, 2$ & 0,877 & 0.2 \\
\hline 06 & $\mathrm{YI}, 3$ & 0,887 & 0.2 \\
\hline
\end{tabular}

tabel di atas menunjukan Uji validitas memperoleh semua pernyataan atau pertanyaan untuk mengukur suatu variabel Celebrity Endorser (X1), iklan instagram (X2) dan keputusan pembelian (Y) adalah seluruhnya valid dikarenakan nilai sig 5\% lebih besar dari 0,2 yang mempunyai arti $r$ tabel di bawah dari r hitung. Sehingga seluruhnya dapat di lanjutkan pada penelitian setelahnya.

\section{Uji Reliabilitas}

reabilitas adalah uji yangi digunakan supaya bisa melihat apakah benar instrument penelitian yang digunakan diperpercaya untuk bisa dipakai sebagai alat untuk menjadikan data terkumpul, berikut adalah uji Reliabelitas. 
Tabel 2. Hasil Uji Reliabilitas

\begin{tabular}{|l|c|c|l|}
\hline Variabele & r-Tabel & $\begin{array}{c}\text { (Alphaa } \\
\text { cronbach }\end{array}$ & penjelasan \\
\hline $\begin{array}{l}\text { Celeberity } \\
\text { endorser }_{1}\end{array}$ & 0,6 & 0,947 & reliabell \\
\hline $\begin{array}{l}\text { Iklan } \\
\text { instagram } X_{2}\end{array}$ & 0,6 & 0,954 & reliabell \\
\hline $\begin{array}{l}\text { Keputusan } \\
\text { pembelianY }\end{array}$ & 0,6 & 0,894 & reliabell \\
\hline
\end{tabular}

Dapat di lihat tabel Hasil uji reabilitas yang berada diatas memperlihatkan data yang telah diperoleh seluruhnya reabel dengan hasil nilai coronbach's alpha Celebrity endorser yaitu dengan jumlah 0,947 iklan instagram 0,954 dan keputusan pembelian 0,894 > (lebih besar) 0,6, sehingga data yang sudah dihasilkan dikatakan reabel karena sangat besar di bandingkan 0,6 maka bisa dipakai sebagai variabele yang di teliti ini.

\section{Uji Data Normalitas}

Di bawah ini merupakan hasil uji normalitas yang memakai analisis grafik P-plot di dalam penelitian ini :

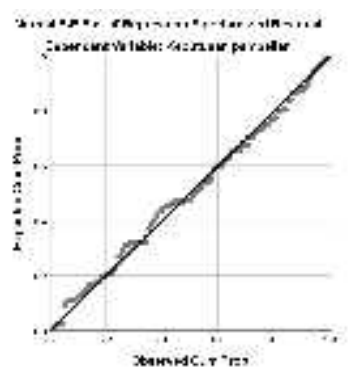

Gambar 2

Uji Normalitas

P-plot yang ada dalam gambar yang berada di atas terdapat titik-titik mengikuti garis diagonalnya dengan lurus dan lurus mendekati garis diagonalnya. Dapat tersimpulkan model regresi telah benarbenar terpenuhi menjadi asumsi normalitas, sehingga dapat melanjutkannya ke analisis data pada penelitian berikutnya. 


\section{$\underline{\text { Regreesi Linierr Berganda }}$}

Regresi lineer berganda di peruntukan perolehan apakah variabel bebas Celebrity endorser dan iklan instagram mempunyai pengaruh dengan bersamaan kepada variabel terikat (keputusan pembelian).

Tabel 3. Penguji regresi Linierr Berganda

\begin{tabular}{lrrr}
\hline Variabele & $\begin{array}{c}\text { Unstanda } \\
\text { rdizeD } \\
\text { Coefficien } \\
\text { ts }(\mathrm{b})\end{array}$ & $\begin{array}{c}\mathrm{t}- \\
\text { hitung }\end{array}$ & sig \\
\hline Constant & 7.389 & 2.983 & .004 \\
\hline Celebrity & .693 & 9.060 & .000 \\
endorser & & & \\
$\left(\mathrm{X}_{1}\right)$ & & & \\
\hline $\begin{array}{l}\text { Iklan } \\
\text { instagram }\end{array}$ & .0251 & 3.131 & .002 \\
$\left(\mathrm{X}_{2}\right)$ & & & \\
Sumber : Lampiran SPSS output Uji Regresi Linier Berganda
\end{tabular}

tabel yang berada di atas tersebut mendapatkan hasil persamaan linierr berganda adalah seperti dibawah :

$$
Y=7,389+0,693 \times 1+0,0251 \times 2+E
$$

B1: Regresi koefisien Celebrity endorser sebesar 0,693, hal tersebut memperlihatkan besarnya pengaruh yang di miliki Celebrity endorser (X1) kepada keputusaan pembelian. Celeberity endorser benar memiliki pengaruh. apabila Celebrity endorser naiknnya persatuaan sehingga nilai dari keputusan pembelian melonjak sebanyak 0,693 B2: Nilai regresi koefisien kiklan isntagram (X2) sebesar 0,0251 variabel iklan instagram memperlihatkan variabel yang memiliki pengaruh sangat besar, Apa bila iklan instagram naiknya keputusan pembelian adalah persatuan. Yang meningkat sebanyak 0,0251.

\section{Pengujia Hipotesis}

\section{Uji t}

di gunakannya Uji t yaitu agar melihat signifikann berpengaruhnya varibel bebas secara signifikan kepada variabel terikat dengan individual.

a. jika sig > 0,05 maka di tolak Ho sedangkan di terima $\mathrm{H} 1$

b. Jika sig < 0,05 maka di terimalah $\mathrm{Ho}$ sedangkan di tolak $\mathrm{H} 1$

. Tabel 4

Hasil Uji t 


\begin{tabular}{lcc}
\hline \multicolumn{1}{c}{$\begin{array}{c}\text { Standardized } \\
\text { Coefficients }\end{array}$} & $\mathrm{t}$ & $\begin{array}{c}\text { Signifika } \\
\mathrm{n}\end{array}$ \\
\hline (Constant) & 2.983 & .004 \\
\hline Celebrity endorser $\left(\mathrm{X}_{1}\right)$ & 9.060 & .000 \\
Iklan instagram $\left(\mathrm{X}_{2}\right)$ & 3.131 & .002 \\
\hline \multicolumn{2}{l}{ Sumber : Output lampiran SPSS 25 }
\end{tabular}

Telah di ketahui pengujian uji t yaitu "Celebrity Endorser (X1) memiliki pengaruh terhadap keputusan pembelian $(\mathrm{Y})$ studi kasus pada Follower instagram Wardah Beauty" supaya bisa mengetahui hubungannya parsial uji hipotesis ini memakai uji-t. berdasarkan tabel yang berada di atas telah di didapatkan Celeberity endorser dengan nilai t-hitung 2.983 dan signifikannya sebanyak 0,004 $<0.05$, dari hasil pengujian tersebut yang berarti hipotesis telah di terima yang mempunyai arti Celebrity endorser memiliki pengaruh kepada keputusan pembelian (Studi kasus pada follower instagram Wardah beauty) telah terbukti kebenarannya. Iklan instagram (X2) memiliki pengaruh kepada keputuusan pembeliann (Y) (Studi kasus pada Follower instagram Wardah Beauty)" dilihat nilai t-hitung variabel iklan instagram adalah 9,060 dan hasil signifikannya $0,000<0,05$, dengan nilai itu yang berarti hipotesis di terima.

\section{Uji F}

Table 5

Uji F

ANOVA

\begin{tabular}{ccr}
\hline Modell & F & \multicolumn{1}{c}{ Signifikan } \\
\hline $\begin{array}{c}\text { Regression } \\
\text { Residual }\end{array}$ & 154,094 & $.000^{\mathrm{b}}$ \\
\hline Total & & \\
\hline
\end{tabular}

a. Variabel Dependent: Keputusan Pembelian

Sumber : Lampiran SPSS 25 Output

Di lihat dari tabel yang telah di uji di atas telah di dapatkan nilai F-hitung sebesar 154,094 serta besarnya hasil signifikanya $0.000<0.05$ dengan nilai yang telah di uji tersebut yang berarti Hipotesis telah di terima yang berarti Celebrity endorser dan iklan instagram mempengaruhi dengan bersam sama terhadap kepada keputusan pembelian studi kasus pada Follower instagram aeardah Beauty.

\section{SIMPULAN}

Berikut adalah kesimpulan di penelitian ini : 
1. Celebrity endorser dengan positif dan signifikann mempengaruhi keputusan pembelian produk Wardah (stusi kasus pada Follower instagram Wardah Beauty). setelah melakukan uji hipotesis dengan memakai uji-t hasil yang di dapat dan diperoleh signifikansi hasilnya $<0,05$. Dimana menunjukkan nilai terdapat pengaruh yang signifikan, maka hipotesis dapat diterima dan kebenarannya terbukti.

2. Iklan Instagram berpengaruh dengan signifikan kepadakeputusan pembelian produk Wardah (studi kasus pada follower instagram Warah Beauty). setelah melakukan uji hipotesis dengan memakai uji-t hasil yang di dapat dan diperoleh nilai signifikansi $<0,05$. Dimana menunjukkan hasil tersebut terdapat pengaruh yang signifikan, maka hipotesis dapat diterima dan kebenarannya terbukti.

Celeberity endorser dan iklan Instagram denga simultan mempengaruhi keputusan pembelian produk Wardah secara simultan. setelah melakukan uji hipotesis menggunakan uji-F yang di dapat dan diperoleh nilai signifikansi $<0,05$. Dimana menunjukkan hasil tersebut terdapat pengaruh yang signifikan, Sehingga hipotesis dapat diterima dan kebenarannya terbukti.

\section{IMPLIKASI}

Berdasarkan perolehan hasil analisis data yang sudah di lakukan, maka saran-saran yang dapat berikan peneliti yang bersangkutan dengan masalah yang diteliti adalah sebagai berikut:

Iklan yang ada di sosial media instagram Wardah beauty memang sudah efektif, tetapi hal tersebut haruslah lebih disempurnakan lagi agar bisa lebih efektif lagi. dengan hasil kesimpulan yang ada, saran kepada instansi agar supaya lebih di perhatikan penggunaan sosial media sebagai alat promosi agar dapat menjalankan kegiatan promosi secara efektif sesuai dengan apa yang di inginkan dan menjadi kebutuhan konsumen. Dalam menggunakan media priklanan instansi atau perusahaan harus hendak berusaha membuat si konsumen mempunya inisiatif untuk melakukan pembelian supaya tujuan dari periklanan tersebut dapat terwujudkan. Untuk membuat ketertarikan pada konsumen dalam memulai tindakan pembelian hal yang harus dilakukan oleh instansi atau perusahaan seperti memilih media iklan yang tepat dan selebrity yang tepat juga menarik misalnya dalam segi penamipalan dan fisik sehingga membuat konsumen lebih memperhatikan iklan yang di buat sehingga konsumen tertarik kepada produk yang telah diiklankan. Disarankan juga kepada perusahaan untuk membuat produk yang khusus untuk laki-laki dan tidak hanya memfokuskan produk wardah kepada perempuan saja.

\section{KETERBATASAN PENELITIAN}

Dalam penelitian ini keterbatasannya adalah peneliti yang tidak banyak mengetahui masalah yang terdapat di dalam instagram Wardah Beauty dan terlalu sedikitnya variabel yang di gunakan yang hanya menyebarkan kuesioner lewat online yaitu berupa google form peneliti sangat berharap untuk peneliti yang akan datang untuk membuat judul yang semenarik mungkin dengan permasalahan yang ada dan menambah variabel di perbanyak lagi. 


\section{DAFTAR RUJUKAN}

Royan, Frans, M. 2004. Marketing Selebrities, Selebrities dalam Iklan dan Strategi Selebritis dalam Memasarkan Diri Sendiri. Penerbit Elek Media Komputindo Kelompok Gramedia. Jakarta.

Wulandari, N. M. R., \& Nurcahya, I. K. 2015. Pengaruh Celebrity Endorser, Brand Image, Brand Trust Terhadap Keputusan Pembelian Clear Shampoo di Kota Denpasar. E-Jurnal Manajemen, $4(11)$.

Widiyanti, W. 2017. Pengaruh Persepsi Kualitas Produk, Citra Merek dan Media Iklan Instagram terhadap Keputusan Pembelian Produk Ninebox (Studi Kasus pada follower instagram@ tempattasdotcom. Cakrawala-Jurnal Humaniora, 17(1).

Simp Terence A., 2003, Pereiklanan Promosi Aspek Tambahan Komonikasi Pemasaran Terpadu, Jakarta: Erlangga

Shimp, Terence A., 2014, Komonikasi Pemasaran Terpadu Dalam Periklanan Dan Promosi, Penerbit Salemba Empat, Jakarta..

Kotller dan Amstrong, 2008. Prinsip-Prinsip Pemasaran Edisi 12 Jilid 1 Penerbit Erlangga Madani, Muhlis dan Tahir, Komunikasi Pemerintah dalam Pengelolaan Tambang di Kabupaten Gowa, Jurnal Ilmu Pemerintahan, Vol. V No. 2 Oktober 2015.

Ferdinand, Agusty. 2014 Metode Penelitian Manajemen Pedoman Penelitian Untuk Penulisan Skripsi, Tesis dan Desertasi IImu Manajemen. Edisi Kedua Semarang. Semarang: Badan Penerbit Universitas Diponegoro.

Sugiyono, 2019. Metode Penelitian Pendekatan Kuantitatif dan Kualitatif, dan R\&D, Alfabeta, Bandung Wardah, Beauty Cosmetics Indonesia. https://www.wardahbeauty.com/ di akses tanggal 16 Oktober, pukul 15:23.

Geser Facebook, Instagram Jadi Sosmed Paling Favorit Di Indonesia https:/ / selular.id/2017/01/geser-facebook-instagram-jadi-sosmed-paling-favorit-diindonesia/ di akses tanggal 29 Oktober 2019 pukul 14:26. 